\title{
Neo-adjuvant treatment of adenocarcinoma and squamous cell carcinoma of the cervix results in significantly different pathological complete response rates
}

Karen Couvreur ${ }^{1}$, Eline Naert ${ }^{1}$, Emiel De Jaeghere ${ }^{1}$, Philippe Tummers ${ }^{2}$, Amin Makar ${ }^{2}$, Pieter De Visschere ${ }^{3}$, Mieke Van Bockstal ${ }^{4}$, Jo Van Dorpe ${ }^{4}$, Wilfried De Neve ${ }^{5}$, Hannelore Denys ${ }^{1}$ and Katrien Vandecasteele ${ }^{5^{*}}$ (D)

\begin{abstract}
Background: Previous studies on cervical cancer reported a worse outcome for adenocarcinoma (AC) compared with squamous cell carcinoma (SCC). Nevertheless, standard treatment remains identical. Insight in the impact of histological types on biological behavior and pathological complete response rates might result in a treatment paradigm shift.

Methods: Clinicopathological characteristics, survival rates and relapse patterns were compared between AC $(n=36)$ and SCC $(n=143)$ cervical cancer patients. Pathological response to treatment was evaluated in the patient subgroup treated with neo-adjuvant chemoradiation followed by surgery (NA-CRT group; $n=84$ ).

Results: In the entire cohort, 5y Disease Specific Survival (DSS) was 97.1 and 84\% for AC and SCC respectively $(p=0.150)$. In the NA-CRT group 5y DSS was 100 and $75.5 \%$ for AC and SCC respectively $(p=0.059)$. Relapse patterns did not differ significantly between AC and SCC in the entire cohort, or in the NA-CRT group. Adenocarcinoma patients treated with NA-CRT showed significantly less pathological complete response compared with SCC patients (AC $=7 \%$, SCC $=43 \%, p=0.027$ ).

Conclusions: There were no statistically significant differences regarding relapse and DSS rates between SCC and AC in the entire cohort, or the NA-CRT group. However, a trend to better 5y DSS of AC in the NA-CRT group was observed. This analysis showed significant differences in treatment responses after NA-CRT: patients with $A C$ responded remarkably less to chemoradiation, resulting in a significantly lower pathological complete response rate. These findings imply a need for a paradigm shift in the treatment of cervical AC patients.
\end{abstract}

Keywords: Adenocarcinoma, Squamous cell carcinoma, Cervical cancer, Differences, Survival, Prognosis

\footnotetext{
* Correspondence: Katrien.vandecasteele@uzgent.be

Denys Hannelore and Vandecasteele Katrien are Last authors contributed

equally

Couvreur Karen, Naert Eline and De Jaeghere Emiel are First authors

contributed equally

${ }^{5}$ Department of Radiation Oncology, UZ Gent, Ghent, Belgium

Full list of author information is available at the end of the article
}

(c) The Author(s). 2018 Open Access This article is distributed under the terms of the Creative Commons Attribution 4.0 International License (http://creativecommons.org/licenses/by/4.0/), which permits unrestricted use, distribution, and reproduction in any medium, provided you give appropriate credit to the original author(s) and the source, provide a link to the Creative Commons license, and indicate if changes were made. The Creative Commons Public Domain Dedication waiver (http://creativecommons.org/publicdomain/zero/1.0/) applies to the data made available in this article, unless otherwise stated. 


\section{Background}

In 2012, 528.000 new cases of cervical cancer were diagnosed worldwide. With an estimated number of 266.000 cervical cancer deaths in the same year, this accounts for $7.5 \%$ of all female cancer deaths globally [1]. About $80 \%$ of all cervical cancers are squamous cell carcinomas (SCC), and about $20 \%$ are adenocarcinomas (AC). Unusual histological variants are rare and account only for a minority of cases [2].

While some studies reported a worse outcome in AC [3-6], others have failed to observe this difference [7-9]. Several studies reported significantly worse survival in patients with AC (compared to SCC) who received definitive radiation (RT) or chemoradiation (CRT) [10-13]. Others suggest that AC has a worse outcome than SCC when treated with RT compared to RT combined with chemotherapy or surgery [14-17]. These results suggest that $\mathrm{AC}$ of the cervix might be less radiosensitive than SCC. Despite etiological, biological and prognostic differences, a specific treatment strategy to tackle AC has not yet been implemented [18]. To date, the recommended management of cervical cancer is mostly independent of its histological subtype but merely guided by staging at diagnosis [18]. For early-stage cervical cancer patients, radical hysterectomy (followed by CRT in case of high-risk for relapse) is the main treatment approach. Only for fertility-sparing surgery (not recommended for patients with small cell neuroendocrine tumors, gastric type adenocarcinoma or adenoma malignum), recommendations differ between AC and SCC. For locally advanced cervical cancer patients, definitive CRT is standard of care [18]. Definitive CRT is a 2-step process consisting of external beam $\mathrm{RT} \pm$ chemotherapy (if possible cisplatin) and a brachytherapeutic boost. Even with the use of image-guided dose-intensified brachytherapy, local relapse arising from CRT-resistant foci is high (3y-local pelvic control rates of $73 \%$ up to $96 \%$, depending on stage and treating center) and remains a major cause of treatment failure [19-21]. In exchange for an improved overall survival (OS), adding chemotherapy to conventional RT has doubled the risk of severe acute hematological and gastro-intestinal toxicity and tripled platelet toxicity [22].

Triggered off by both the high local recurrence and the toxicity rates we challenged the gold standard by investigating the role of surgery after definitive CRT [2325], allowing a pathological evaluation of treatment response in this specific group of cervical cancer patients.

The goal of this retrospective analysis was to determine the clinicopathological characteristics of patients with cervical cancer treated at a single university center and to investigate the differences in survival and relapse rates between AC and SCC of the cervix. These characteristics, extended with pathological treatment response, have been investigated in the subgroup of patients treated with CRT followed by surgery.

\section{Methods \\ Study population}

After institutional ethics committee approval was obtained (B670201628633), the medical records of FIGO stage IA1-IVA cervical cancer patients were reviewed. All patients were treated between 1/1/2005 and 31/12/ 2015. Twenty-eight out of 207 patients were excluded due to following reasons: treatment for recurrent disease or metastatic disease at diagnosis $(n=9$ and $n=8$, respectively), treatment received in another center $(n=7)$, treatment interrupted according to patients' wish $(n=1)$ or general non-cervical cancer (or its treatment) related problems $(n=3)$. Independent checks were performed for patient, tumor, treatment and outcome characteristics to identify and correct major reporting errors.

The patient cohort was classified according to histological type and FIGO stage: adenocarcinoma (AC) including adenosquamous subtypes $(n=36)$ versus squamous cell carcinoma (SCC; $n=143$ ) and early (FIGO stage IA to IB1) versus advanced stages (FIGO stage IB2 to IVA). Following patient data were registered: age, smoking, histological subtype, FIGO stage and TNM classification, tumor grade, presence or absence of lymphovascular space invasion (LVSI) and pelvic lymph node status, thrombocyte count, tumor size and depth of invasion in case of primary surgery (maximum measurable distance in $\mathrm{cm}$ ), type of treatment (including concomitant administration of chemotherapy), date of diagnosis, date of end of therapy, date of last follow-up, date and localization of first relapse, date and cause of death. Thrombocytosis was defined as a platelet count above $450.000 / \mu \mathrm{L}$.

\section{Treatment, response evaluation, follow-up and relapse pattern}

Pre-treatment imaging consisted of magnetic resonance imaging (MRI) of the pelvis and whole body ${ }^{18}$ Fluorodeoxyglucose positron emission tomography - computed tomography $\left({ }^{18} \mathrm{FDG}\right.$ PET-CT). The following treatment regimens were used:

1) surgery;

2) surgery + adjuvant chemoradiation (CRT);

3) neo-adjuvant chemoradiation (NA-CRT) + surgery according to the study protocol in case of FIGO stage IB2-IVA [25]. This group contained all patients who were intended to undergo surgery, including those with an inoperable tumor due to insufficient response to NA-CRT, and is called the NA-CRT group from this point onwards;

4) definitive CRT (surgery was never intended). 
If possible, chemotherapy (C) was administered concomitantly and consisted of weekly single-agent cisplatin $\left(40 \mathrm{mg} / \mathrm{m}^{2}\right)$. RT was performed in 25 fractions using an Intensity Modulated Arc Technique up to a) a minimal dose (D98) of 45Gy to the whole target in the adjuvant CRT group and b) a minimal dose (D98) of $45 \mathrm{~Gy}$ to the elective lymph nodes and target volume and 62/60Gy (using a simultaneously integrated boost) to the tumor/affected lymph nodes in the NA-CRT group (as previously described in detail) [24-26]. From 1/2/2009 onwards, para-aortic lymph node irradiation was performed in case of pathological enlarged (lymph node with shortest axis > $10 \mathrm{~mm}$ or round lymph node with axis $>8 \mathrm{~mm}$ ) or PET-positive pelvic lymph nodes. Brachytherapy was applied a) from stage IB2 onwards in the adjuvant CRT group and b) in case of doubtful or positive margins after surgery in the NA-CRT group.

Surgery consisted of type II Wertheim hysterectomy with pelvic lymphadenectomy performed within 6 to 8 weeks after ending NA-CRT. In the NA-CRT group, selective nodal removal was only performed in case of pathological enlarged or PET-positive pelvic lymph nodes on the diagnostic ${ }^{18}$ FDG PET-CT (instead of pelvic lymphadenectomy). After surgery in case of NA-CRT treatment, response was categorized as: 1) pathological complete response ( $\mathrm{pCR}$ ): no evidence for the presence of viable tumor cells; 2) incomplete pathological response: any amount of viable tumor cells.

Patients were followed-up weekly during treatment, and 1 and 3 months thereafter. Follow-up was scheduled 3 -monthly during the first 2 years, 6-monthly during year 3-5 and annually thereafter.

Relapse patterns were categorized into four groups: 1) locoregional relapse (relapse at the tumor site and pelvic lymph nodes); 2) distant nodal relapse (relapse at distant lymph nodes outside the pelvis, including the para-aortic, supraclavicular and inguinal nodes); 3) non-nodal distant relapse (peritoneal, visceral or bone metastases) and; 4) combined (any of previous categories occurring synchronously as 1st event of relapse).

\section{Survival rate definitions}

Overall survival (OS) was defined as the time from date of histological diagnosis to either the date of death due to any cause or the date of last follow-up. In disease-specific survival (DSS) analysis, only deaths caused by cervical cancer or due to a cancer-related cause were considered as events. Disease-free survival (DFS) was defined as the time from end of therapy to the occurrence of relapse. Relapse was confirmed either histologically or clinically when follow-up imaging was highly suggestive for recurrence.

\section{Statistical analysis}

The primary goal was to compare survival rates and relapse pattern between $\mathrm{AC}$ and SCC in the entire patient cohort. The secondary goal was to evaluate a difference in survival, relapse pattern and pathological treatment response to NA-CRT between $\mathrm{AC}$ and $\mathrm{SCC}$ in the NA-CRT group.

Data were analyzed with the $R$ environment for statistical computing [27]. Balanced patient characteristics were tested with nonparametric Wilcoxon tests for equality of means, and Pearson's chi-square tests for equality of proportions [28, 29]. Kaplan-Meier curves were applied to estimate overall survival (OS), disease-specific survival (DSS) and disease-free survival (DFS) [30]. Univariate and multivariate survival differences between Kaplan-Meier curves were evaluated with the Cox proportional hazards regression and log-rank test [31]. All tests were evaluated with a 95\% confidence interval.

\section{Results \\ Patient and treatment characteristics}

Data of 179 cervical cancer patients were analyzed, of which 36 were AC and 143 were SCC. Median age at diagnosis was 50 years (range 24-89); median follow-up was 50 months (3-148). FIGO stage distribution was as follows: $\mathrm{IA}=15(8 \%) ; \mathrm{IB}=71(40 \%)$; IIA $=6 \quad(3 \%) ; \quad$ IIB $=58 \quad(32 \%) ; \quad$ IIIA $=8 \quad(5 \%) ; \quad$ IIIB $=14$ $(8 \%)$; and IVA $=7(4 \%)$. Age, follow-up period, nodal status, depth of invasion and LVSI were similar between both groups (Table 1). Lymph node metastases were present in 28 and $38 \%$ of AC and SCC patients $(p=0.319)$ respectively. In $5 \mathrm{SCC}$ patients nodal status could not be assessed. Mean tumor size was significantly larger for SCC $(4.3 \mathrm{~cm})$ than AC $(3.5 \mathrm{~cm})$ $(p=0.028)$; ACs were more often stage IB1 (50\% versus $25 \%$ for SCC; $p=0.007)$ and well differentiated (31\% versus $6 \%$ in SCC; $p=0.0001$ ). Squamous cell carcinomas were more often moderately differentiated than AC (48\% versus $25 \%$ resp.; $p=0.024)$. The treatment regimens were not significantly different between AC and SCC (Table 2). 14/36 (39\%) AC and 70/143 (49\%) SCC patients were treated with NA-CRT intent respectively (NA-CRT group). Seven patients (all SCC) did not respond sufficiently (persisting parametrial invasion) to NA-CRT and did not undergo surgery. Apart from median follow-up (AC: $59 \mathrm{~m}$ versus SCC: $36 \mathrm{~m} ; p=0.033$ ) and tumor grade (AC were more often well differentiated: $21 \%$ versus $3 \% ; p=0.039$ or had an unknown differentiation grade: $50 \%$ versus $20 \% ; p=0.042$ ) patient characteristics in the NA-CRT group were similar between the $\mathrm{AC}$ and SCC groups (Table 1). 
Table 1 Patient characteristics

\begin{tabular}{|c|c|c|c|c|c|c|}
\hline \multirow[t]{3}{*}{$n$} & \multicolumn{3}{|l|}{ Entire Cohort } & \multicolumn{3}{|c|}{ Neo-Adjuvant Chemoradiation group } \\
\hline & \multirow{2}{*}{$\begin{array}{l}A C \\
36\end{array}$} & \multirow{2}{*}{$\begin{array}{l}\text { SCC } \\
143\end{array}$} & \multirow[t]{2}{*}{$\mathrm{p}$} & \multirow{2}{*}{$\begin{array}{l}\mathrm{AC} \\
14\end{array}$} & \multirow{2}{*}{$\begin{array}{l}\text { SCC } \\
70\end{array}$} & \multirow[t]{2}{*}{$p$} \\
\hline & & & & & & \\
\hline Age in $y$; median (range) & $48(27-82)$ & $51(24-89)$ & 0.196 & $47.5(38-65)$ & $57(24-89)$ & 0.070 \\
\hline Follow-up in m; median (range) & $54(7-138)$ & $50(3-148)$ & 0.218 & $59(7-135)$ & $36(7-133)$ & 0.033 \\
\hline \multicolumn{7}{|l|}{ Tumor FIGO stage, n (\%) } \\
\hline IA & $1(3)$ & $1(1)$ & 0.862 & 0 & 0 & \\
\hline$|A|$ & $0(0)$ & $5(3)$ & 0.567 & 0 & 0 & \\
\hline $\mathrm{A} 2$ & $0(0)$ & $8(6)$ & 0.317 & 0 & 0 & \\
\hline IB & $2(6)$ & $2(1)$ & 0.380 & 0 & 0 & \\
\hline |B1 & $18(50)$ & $36(25)$ & 0.007 & $1(7)$ & $1(1)$ & 0.749 \\
\hline IB2 & $2(6)$ & $11(8)$ & 0.934 & $2(14)$ & $6(9)$ & 0.868 \\
\hline$\| \mathrm{A}$ & $0(0)$ & $2(1)$ & 1 & 0 & 0 & \\
\hline$\| \mathrm{A} 1$ & $0(0)$ & $1(1)$ & 1 & 0 & 0 & \\
\hline$\| \mathrm{A} 2$ & $2(6)$ & $1(1)$ & 0.193 & $1(7)$ & 0 & 0.368 \\
\hline$\| B$ & $9(25)$ & $49(34)$ & 0.388 & $8(57)$ & $43(61)$ & 1 \\
\hline$\| \mathrm{A}$ & $0(0)$ & $8(6)$ & 0.317 & 0 & $6(9)$ & 0.570 \\
\hline$\| \mathrm{IIB}$ & $2(6)$ & $12(8)$ & 0.826 & $2(14)$ & $8(11)$ & 1 \\
\hline IVA & $0(0)$ & $7(5)$ & 0.382 & 0 & $6(9)$ & 0.570 \\
\hline \multicolumn{7}{|l|}{ Tumor TNM stage, $n(\%)$} \\
\hline I & $21(58)$ & $52(36)$ & 0.027 & $2(14)$ & $2(3)$ & 0.251 \\
\hline$\|$ & $8(22)$ & $33(23)$ & 1 & $7(50)$ & $27(39)$ & 0.619 \\
\hline III & $7(19)$ & $50(35)$ & 0.113 & $5(36)$ & $34(49)$ & 0.557 \\
\hline IV & $0(0)$ & $8(6)$ & 0.317 & $0(0)$ & $7(10)$ & 0.480 \\
\hline \multicolumn{7}{|l|}{ Pelvic lymph node status, $n$ (\%) } \\
\hline negative & $26(72)$ & $83(58)$ & 0.172 & $11(79)$ & $34(49)$ & 0.078 \\
\hline positive & $10(28)$ & $55(38)$ & 0.319 & $3(21)$ & $36(51)$ & 0.078 \\
\hline unknown, n (\%) & $0(0)$ & $5(3)$ & 0.567 & $0(0)$ & $0(0)$ & 1 \\
\hline \multicolumn{7}{|l|}{ Tumor size, $\mathrm{cm}$} \\
\hline median (range) & $3.5(0.4-7.0)$ & $4.3(0.1-10.5)$ & 0.028 & $4.3(2.3-7)$ & $5.5(1.8-8.2)$ & 0.056 \\
\hline unknown, n (\%) & $2(6)$ & $24(17)$ & 0.149 & 0 & $2(3)$ & 1 \\
\hline \multicolumn{7}{|l|}{ Depth invasion, $\mathrm{cm}$} \\
\hline median (range) & $1(0.3-1.7)$ & $0.8(0.1-5)$ & 0.905 & - & - & \\
\hline primary surgery, n (\%) & $13(36)$ & $46(32)$ & 0.801 & - & - & \\
\hline unknown, n (\%) & $9(25)$ & $14(10)$ & 0.031 & - & - & \\
\hline no primary surgery, n (\%) & $14(39)$ & $83(58)$ & 0.061 & - & - & \\
\hline \multicolumn{7}{|l|}{ Chemotherapy concomitant, $n$ (\%) } \\
\hline yes & - & - & & $13(93)$ & $62(89)$ & 1 \\
\hline no & - & - & & $1(7)$ & $8(11)$ & 1 \\
\hline \multicolumn{7}{|l|}{ Differentiation status, n (\%) } \\
\hline well & $11(31)$ & $9(6)$ & 0.0001 & $3(21)$ & $2(3)$ & 0.039 \\
\hline moderate & $9(25)$ & $68(48)$ & 0.024 & $3(21)$ & $32(46)$ & 0.166 \\
\hline poor & $7(19)$ & $43(30)$ & 0.288 & $1(8)$ & $22(32)$ & 0.126 \\
\hline unknown & $9(25)$ & $23(16)$ & 0.315 & $7(50)$ & $14(20)$ & 0.043 \\
\hline
\end{tabular}

LVSI, n(\%) 
Table 1 Patient characteristics (Continued)

\begin{tabular}{|c|c|c|c|c|c|c|}
\hline \multirow[t]{3}{*}{$n$} & \multicolumn{3}{|c|}{ Entire Cohort } & \multicolumn{3}{|c|}{ Neo-Adjuvant Chemoradiation group } \\
\hline & $\overline{A C}$ & SCC & \multirow[t]{2}{*}{$p$} & $\overline{A C}$ & SCC & \multirow[t]{2}{*}{$p$} \\
\hline & 36 & 143 & & 14 & 70 & \\
\hline negative & $7(19)$ & $14(10)$ & 0.187 & - & - & \\
\hline positive & $11(31)$ & $32(22)$ & 0.419 & - & - & \\
\hline unknown & $4(11)$ & $14(10)$ & 1 & - & - & \\
\hline no primary surgery & $14(39)$ & $83(58)$ & 0.061 & - & - & \\
\hline \multicolumn{7}{|l|}{ Patient outcome, $n(\%)$} \\
\hline alive/censored & $33(92)$ & $107(75)$ & 0.0498 & $13(93)$ & $46(66)$ & 0.088 \\
\hline disease-specific death & $2(6)$ & $20(14)$ & 0.274 & 0 & $15(21)$ & 0.126 \\
\hline other cause of death & $0(0)$ & $14(10)$ & 0.107 & 0 & $8(11)$ & 0.406 \\
\hline unknown & $1(3)$ & $2(1)$ & 1 & $1(7)$ & $1(1)$ & 0.749 \\
\hline
\end{tabular}

AC adenocarcinoma, SCC squamous cell carcinoma, $n$ amount, $p$ p-value, $y$ years, LVSI lymph vascular space invasion, significant $\mathrm{p}$-values $(p<0.05)$ are presented in bold

\section{Outcome}

\section{Survival}

Thirty-nine deaths were reported, 3 in the AC group and 36 in the SCC, resulting in a 5y OS rate of 94.4 and $73.2 \%(p=0.034)$ respectively. The 5y OS rate for early (FIGO stage IA to IB1) AC and SCC was 100 and $89.4 \%$ $(p=0.408)$ respectively. The $5 y$ OS for advanced (FIGO stage IB2 to IVA) AC and SCC was 87.5 and $63.1 \%$ respectively $(p=0.120)$. The SCC group showed more non-disease-specific deaths $(14 / 36,39 \%$ of all SCC deaths) compared to the AC group (0/3) (Table 1). Although this difference was not statistically significant $(p$ $=0.107$ ), we preferred using DSS to correct for this random effect. Both FIGO (5-y DSS is 94.7, 88, 64.1 and $28.6 \%$ in FIGO stage I, II, III and IV respectively) and TNM stage (5-y DSS is 95.3, 92.2, 77.2 and $41.7 \%$ in TNM stage I, II, III and IV respectively) had an impact on 5y DSS (Fig. 1a and b). The estimated 5y DSS in the entire cohort, AC and SCC group amounted 86.8, 97.1 and $84.0 \%$ respectively (Fig. $1 c),(p=0.150)$. The estimated 5y DSS did not differ significantly between AC and SCC in both the early and advanced stage cohort
(AC/SCC: early 100\%/93.3\% and advanced 93.3\%/78.6\%; $p=0.847 / 0.232$ ) (Fig. 1d and e).

Five-year DSS amounted 79.8\% in the overall NA-CRT group $(n=84)$, and it was 100 and $75.5 \%(p=0.060)$ for the AC $(n=14)$ and SCC patients $(n=70)$ in this group respectively (Fig. 1f).

The estimated 5-year DFS rates were 73.8 and $79.2 \%$ $(p=0.809)$ in the entire cohort for the AC and SCC group respectively. The estimated 5-year DFS rates were 61.5 and $72.3 \%(p=0.558)$ in the NA-CRT group for AC and SCC respectively (Fig. $2 \mathrm{a}$ and $\mathrm{b}$ ).

\section{Pathological complete response rates in the NA-CRT group}

Seventy-seven patients treated with NA-CRT intent were operated upon. A pCR was obtained in 7\% (1/14) and $43 \%(27 / 63)$ of the AC and SCC patients respectively $(p=0.027)$. This difference remained statistically significant when all non-operated tumors $(\mathrm{n}=7$, all SCC) were considered as incomplete pathological response: 7\% (1/14) versus 39\% (27/70) pCR for AC and SCC respectively $(p=0.049)$.

Table 2 Primary treatment by tumor histology

\begin{tabular}{|c|c|c|c|}
\hline Treatment, n (\%) & $A C$ & SCC & $p$ \\
\hline Surgery & $10(28)$ & $23(16)$ & 0.169 \\
\hline Surgery + adjuvant chemoradiation ${ }^{\mathrm{ab}}$ & $12(33)$ & $36(25)$ & 0.437 \\
\hline Neo-adjuvant chemoradiation ${ }^{a}$ with intent for surgery ${ }^{c}$ & $14(39)$ & $70(49)$ & 0.371 \\
\hline Definitive chemoradiation $^{\text {ad }}$ & $0(0)$ & $12(8)$ & 0.154 \\
\hline Brachytherapy alone $e^{e}$ & $0(0)$ & $1(1)$ & 1 \\
\hline Neo-adjuvant chemotherapy + conization $^{f}$ & $0(0)$ & $1(1)$ & 1 \\
\hline
\end{tabular}

AC adenocarcinoma $(n=36)$, SCC Squamous Cell Carcinoma $(n=143) ;{ }^{a}$ If possible, chemotherapy $(C)$ was administered concomitantly and consisted of weekly single-agent cisplatin at $40 \mathrm{mg} / \mathrm{m}^{2} ;{ }^{b}$ In $11 / 33 \mathrm{AC} / \mathrm{SCC}$ patients this includes a brachytherapeutic boost; ${ }^{\mathrm{c}} 7 \mathrm{SCC}$ patients did not receive surgery and $1 / 3 \mathrm{AC} / \mathrm{SCC}$ patients received a brachytherapeutic boost due to positive or doubtful margins; ${ }^{e}$ due to co-morbidities; ${ }^{f}$ fertility sparing 

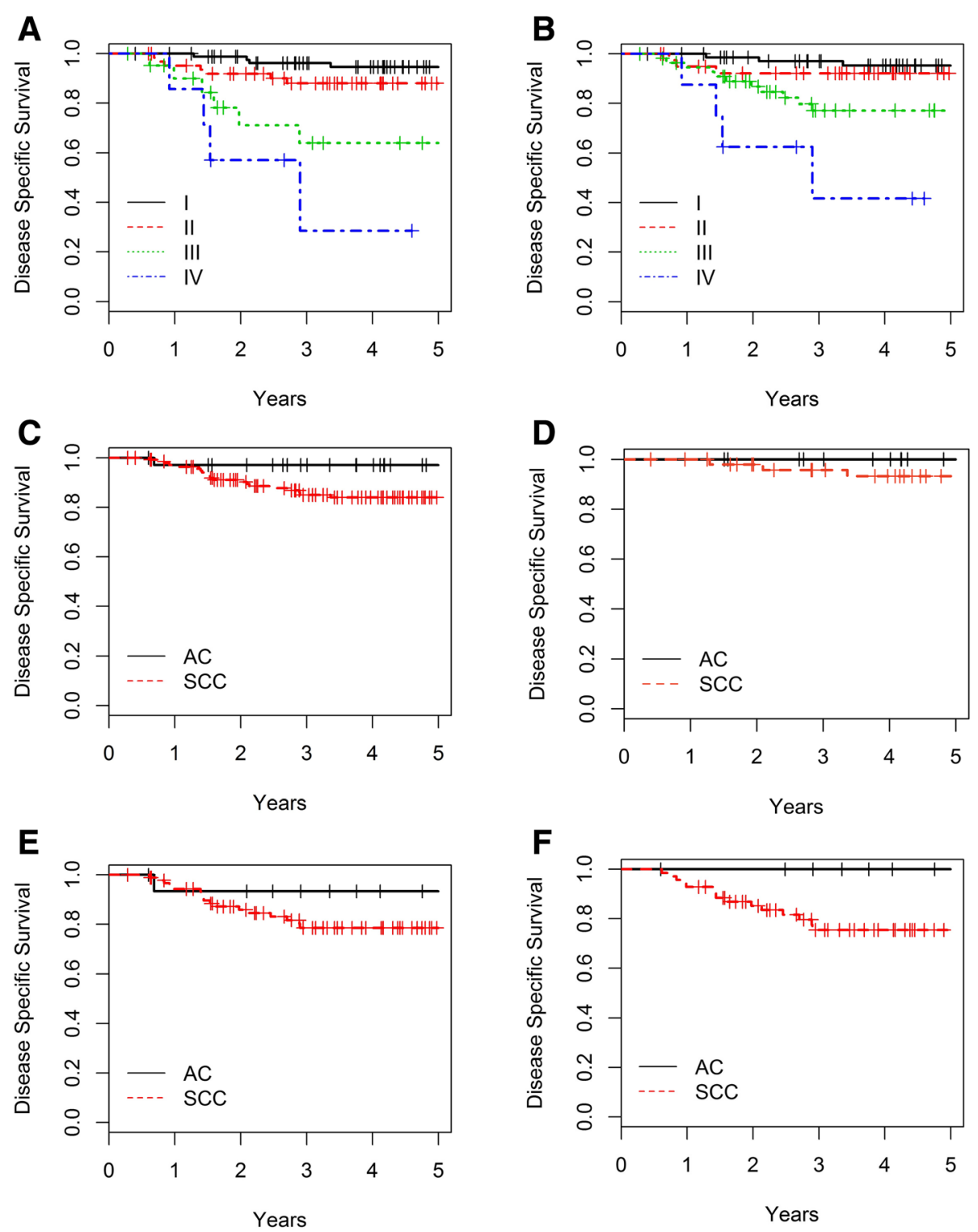

Fig. 1 a. Disease-Specific Survival (DSS) and FIGO stage: I $(n=86,5 y$-DSS 94.7\%), II $(n=64,5 y$-DSS 88.0\%), III $(n=22,5 y$-DSS 64.1\%) and IV $(n=7,5 y$-DSS 28.6\%). (III and IV, $p<0.001)$. b. DSS and TNM stage: I $(n=73,5 y$-DSS 95.3\%), II $(n=41,5 y$-DSS 92.2\%), III $(n=57,5 y$-DSS $77.2 \%)$ and IV ( $n=8,5 y$-DSS 41.7\%). (III and IV, p < 0.001). C-F. DSS and histology: c. Entire cohort: adenocarcinoma (AC): $n=36,5 y-$ DSS: $97.1 \%$ and Squamous Cell Carcinoma (SCC): $n=143,5 y$-DSS 84.0\%; $p=0.150$. d. Entire cohort; early stages: AC: $n=20,5 y$-DSS: $100 \%$ and SCC: $n=52,5 y$-DSS: 93.3\%; $p=0.847$. e. Entire cohort; advanced stages: AC: $n=16,5 y$-DSS: $93.3 \%$ and SCC: $n=91,5 y-D S S: 78.6 \% ; p=0.232$. f. NA-CRT group: AC: $n=14,5 y$-DSS: $100 \%$ and SCC: $n=70 ; 5 y$-DSS $75.5 \% ; p=0.059$

\section{Relapse}

The relapse rate for the entire cohort was $8 / 36$ (22\%) and 28/143 (20\%) for AC and SCC respectively ( $p=$ 0.904) (Additional file 1: Table S1). In AC, site of first relapse was $1 / 8(12.5 \%)$ locoregional, $1 / 8$ (12.5\%) distant nodal, 4/8 (50\%) distant non-nodal and 2/8 (25\%) a combination of previous categories. In SCC, the site of first relapse was 11/28 (39\%) locoregional, 1/28 (4\%) distant nodal, 5/28 (18\%) distant non-nodal and in 11/28 (39\%) of the cases a combination of previous categories.
No significant difference was found. In the NA-CRT group, relapse rate and pattern were not significantly different: 5/14 (36\%) and 19/70 (27\%) for AC and SCC respectively $(p=0.746)$. In $\mathrm{AC}$, the site of first relapse was 0/5 (0\%) locoregional, $1 / 5$ (20\%) distant nodal, 3/5 (60\%) distant non-nodal and in $1 / 5(20 \%)$ of cases a combination of previous categories. In SCC, the site of first relapse was 8/19 (42\%) locoregional, $1 / 19$ (5\%) distant nodal, 3/19 (16\%) distant non-nodal and 7/19 (37\%) combined. 

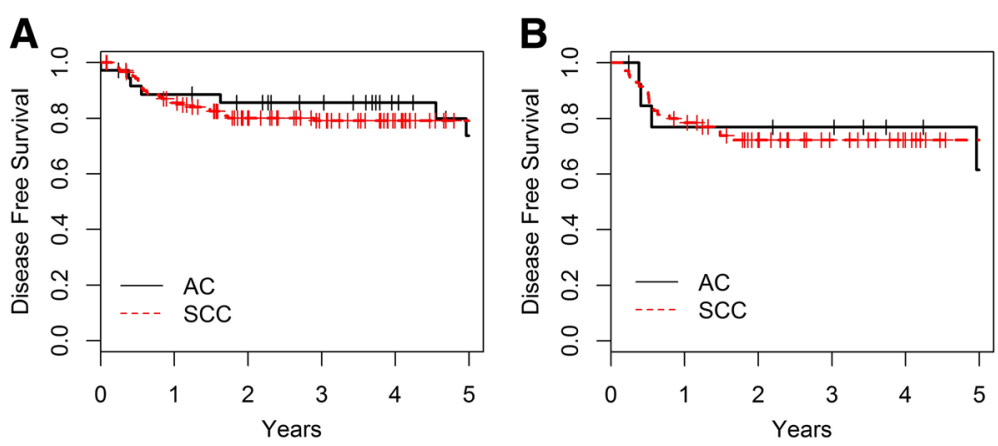

Fig. 2 Disease-Free Survival and histology: a. Entire cohort. Adenocarcinoma (AC): $n=36 ; 5 y-D F S ~ 73.8 \%$ and Squamous Cell Carcinoma (SCC): $n=$ $143,5 y$-DFS 79.2\%; $p=0.809$. b. NA-CRT group. AC: $\mathrm{n}=14 ; 5 y$-DFS $61.5 \%$ and SCC: $\mathrm{n}=70,5 \mathrm{y}$-DFS 72.3\%; $p=0.558$. $\mathrm{c}$

\section{Uni- and multivariate analysis}

Univariate analysis (Additional file 1: Table S2) showed that lymph node involvement $(\mathrm{HR}=2.968, p=0.016)$, tumor size $(\mathrm{HR} / \mathrm{cm}=1.53)$ and advanced FIGO stage $(\mathrm{HR}=3.58, \quad p=0.021) \quad$ significantly influenced DSS. Thrombocytosis, tumor differentiation and LVSI did not. In multivariate analysis, only FIGO stage was observed to have a significant impact on DSS (Additional file 1: Table S3).

\section{Discussion}

In clinical practice, $\mathrm{AC}$ seems to be less responsive to therapy and more frequently associated with earlier distant metastases. Population-based studies indicate a rising incidence of AC despite cytological screening [32]. In addition, recent studies identified certain subtypes of non-HPV related adenocarcinoma, like gastric subtypes with worse prognosis and higher tendency for adnexal and distant metastases. Although a more aggressive approach of $\mathrm{AC}$ has often been subject of intensive research, treatment of both histological types of cervical cancer currently remains almost identical. The purpose of this study was to test the hypothesis that both histological subtypes of cervical carcinoma have different survival, relapse patterns and response rates to treatment and thus require tailored therapy.

There are several limitations to this study, some of them inherent to the retrospective design, such as recall and confounding bias. LVSI and depth invasion were often missing in the histopathological reports. In addition, our study reports on a heterogeneous group of patients including all stages with different types of treatment. Analyses were not corrected for treatment type. All consecutively treated patients within the reported period were included. Therefore, all findings are restricted to this population sample. A power analysis was conducted, and the significance tests had $80 \%$ power to detect a difference in DSS of $12 \%$ or more between advanced AC and SCC patients. A larger sample size is needed to detect smaller survival differences. Nevertheless, despite the aforementioned limitations, we observed some very interesting and intriguing phenomena.

The study population was well balanced with the exception of FIGO stage IB1 and TNM stage 1 patients, smaller tumors and well differentiated tumors that were overrepresented in the AC population. Moderately differentiated tumors were overrepresented in the SCC population. A higher percentage of stage I [13] and well differentiated [33] AC patients was also observed by others. Despite the overrepresentation of FIGO stage IB1, small and well differentiated tumors in the AC population, we failed to observe a difference in treatment regimen between $\mathrm{AC}$ and $\mathrm{SCC}$. We assume that this lack of difference is due to the small patient sample size and the high amount of treatment options. If we reduce the treatment options to primary surgical (including adjuvant CRT or fertility sparing neo-adjuvant chemotherapy and conization) and primary RT intent (including NA-CRT; definitive CRT and brachytherapy alone) we do find more AC (22/36) than SCC (60/143) patients primarily operated upon $(p=0.039)$.

In contrast to our study, several studies did report a worse prognosis for AC (Table 3) [3, 4, 6-8, 34-38]. Three out of 8 early AC/SCC and 9 out of 19 advanced AC/SCC comparisons show a significant difference in survival, all resulting in a worse outcome for AC compared to SCC. Most of the statistically non-significant comparisons had limited AC population sizes, limiting the power of the respective tests. In addition, if the variations in the results reflect normal study-to-study differences, then we also would expect to find studies claiming better AC prognosis. Yet to the best of our knowledge, we failed to find any study reporting a significant better $\mathrm{AC}$ survival. In this report, $5 \mathrm{y}$ OS of advanced stage $\mathrm{AC}$ is $87.5 \%$, which is higher than the results of most studies reported in Table 3 (5 to 87\%) [39]. No significant difference in DSS was noted between $\mathrm{AC}$ and SCC in the entire study cohort. However, a trend towards a better DSS for AC was seen in the 
Table 3 Literature Overview

\begin{tabular}{|c|c|c|c|c|c|c|c|c|}
\hline \multirow[t]{2}{*}{ Source } & \multirow[t]{2}{*}{ Period } & \multirow[t]{2}{*}{ Stage } & \multicolumn{2}{|l|}{$A C$} & \multicolumn{2}{|l|}{ SCC } & \multirow[t]{2}{*}{ Sign. } & \multirow[t]{2}{*}{$A C-S C C$} \\
\hline & & & $n$ & $5 y$ OS & $n$ & $5 \mathrm{yOS}$ & & \\
\hline \multicolumn{9}{|l|}{ Early } \\
\hline Hopkins et al. [4] & 1970-1985 & I & 124 & 0.6 & 370 & 0.9 & $x$ & -0.3 \\
\hline Shingleton et al. [30] & 1984-1990 & । & 174 & 0.84 & 1136 & 0.84 & & 0 \\
\hline Couvreur et al. ${ }^{\mathrm{a}}$ & 2005-2015 & $\mid A-1 B 1$ & 20 & 1 & 52 & 0.89 & & 0.11 \\
\hline Teke et al. [8] & 1996-2000 & $|A-| \mid B$ & 33 & 0.77 & 218 & 0.73 & & 0.04 \\
\hline Ayhan et al. [31] & 1980-1997 & $\mathrm{IB}$ & 67 & 0.84 & 454 & 0.88 & & -0.04 \\
\hline Eifel et al. [32] & 1960-1989 & IB & 229 & 0.72 & 1538 & 0.81 & $x$ & -0.09 \\
\hline Nakanishi et al. [34] & 1976-1995 & $\mathrm{IB}$ & 104 & 0.88 & 405 & 0.96 & $x$ & -0.08 \\
\hline Galic et al. [3] & 1998-2005 & $\mid \mathrm{B} 1$ & 1094 & 0.85 & 3214 & 0.88 & & -0.03 \\
\hline Shimada et al. [6] & 1997-2003 & $\mid \mathrm{B} 1$ & 184 & 0.92 & 258 & 0.95 & & -0.03 \\
\hline \multicolumn{9}{|l|}{ Advanced } \\
\hline Galic et al. [3] & 1998-2005 & IB2 & 343 & 0.68 & 1701 & 0.69 & & -0.01 \\
\hline Shimada et al. [6] & 1997-2003 & IB2 & 39 & 0.76 & 67 & 0.74 & & 0.01 \\
\hline Irie et al. [33] & 1981-1996 & $|\mathrm{B}-| \mid \mathrm{A}$ & 50 & 0.78 & 198 & 0.92 & & -0.14 \\
\hline Shimada et al. [6] & 1997-2003 & $|\mathrm{B}-| \mid \mathrm{B}$ & 280 & 0.87 & 540 & 0.83 & & 0.04 \\
\hline Hopkins et al. [4] & 1970-1985 & $\|$ & 40 & 0.47 & 186 & 0.62 & $x$ & -0.15 \\
\hline Shingleton et al. [30] & 1984-1990 & $\|$ & 102 & 0.57 & 1073 & 0.67 & $x$ & -0.11 \\
\hline Galic et al. [3] & 1998-2005 & $\| A$ & 202 & 0.46 & 1488 & 0.58 & $x$ & -0.13 \\
\hline Shimada et al. [6] & 1997-2003 & $\| A$ & 11 & 0.55 & 83 & 0.87 & $x$ & -0.33 \\
\hline Galic et al. [3] & 1998-2005 & $\| B$ & 424 & 0.46 & 3754 & 0.55 & $x$ & -0.09 \\
\hline Katanyoo et al. [7] & 1980-1997 & $\| B$ & 85 & 0.72 & 170 & 0.71 & & 0.01 \\
\hline Shimada et al. [6] & 1997-2003 & $\| B$ & 46 & 0.63 & 132 & 0.79 & $x$ & -0.16 \\
\hline Couvreur et al. ${ }^{a}$ & $2005-2015$ & IB2-IVA & 16 & 0.88 & 91 & 0.63 & & 0.25 \\
\hline Hopkins et al. [4] & 1970-1985 & III & 25 & 0.08 & 114 & 0.36 & $x$ & -0.28 \\
\hline Shingleton et al. [30] & 1984-1990 & III & 47 & 0.3 & 672 & 0.4 & & -0.1 \\
\hline Galic et al. [3] & 1998-2005 & $\| \mathrm{A}$ & 80 & 0.16 & 695 & 0.34 & $x$ & -0.18 \\
\hline Galic et al. [3] & 1998-2005 & $\| \mathrm{B}$ & 238 & 0.2 & 2568 & 0.31 & $x$ & -0.11 \\
\hline Katanyoo et al. [7] & 1995-2008 & IIIB-IVA & 56 & 0.41 & 112 & 0.47 & & -0.06 \\
\hline Shingleton et al. [30] & 1984-1990 & IV & 41 & 0.05 & 287 & 0.13 & & -0.08 \\
\hline Galic et al. [3] & 1998-2005 & IVA & 82 & 0.08 & 622 & 0.17 & & -0.09 \\
\hline Galic et al. [3] & 1998-2005 & IVB & 281 & 0.09 & 959 & 0.06 & & 0.04 \\
\hline
\end{tabular}

AC adenocarcinoma, SCC Squamous cell carcinoma, $n$ number, $5 y O S 5$ year overall survival period: years of enrollment of patients, Sign significance with p-value $<$ 0.05 (all significance levels lie between 0.01 and 0.05 ); AC-SCC: $5 y$ survival data AC minus 5y survival data SCC resulting in a delta value

acurrent article

NA-CRT group $(p=0.059)$. A possible explanation is the more aggressive treatment used, where $78 \%$ of the advanced stage patients had surgery after NA-CRT. The randomized trial of Landoni et al. compared surgery to RT in patients with FIGO IB-IIA CC and reported equivalent survival rates [15]. However, patients with AC treated with hysterectomy had better DFS than patients treated with definitive RT $(66 \%$ vs $47 \%, p=$ 0.02) suggesting that $A C$ may be more resistant to RT [15]. Other reports confirmed that AC of the cervix might be less radiosensitive than SCC $[10-13,40]$.
In a group of patients treated with definitive CRT, Chen et al. [10] showed that a complete pathological treatment response was significantly more present in the SCC subtype compared to the adenosquamous/ AC subtypes $(87.1 \%$ v s $71.4 \%, p=0.018)$, and nearly $1 / 3$ of the adenosquamous/AC subtypes had persistent tumor at the cervix 3 months after completing RT. Huang et al. [11] reported $41 \%$ residual disease in the cervix after definitive RT for AC. Our results complement these findings in advanced stage cervical cancer, where $\mathrm{pCR}$ is significantly less present in $\mathrm{AC}(\mathrm{AC}=$ 
$7 \%, \mathrm{SCC}=43 \%, p=0.027)$. This is not due to FIGO stage or size of the tumor since the AC group had more favorable patient characteristics (smaller tumor size, well differentiated, Table 1). Several potential mechanisms of radioresistance and predictors of treatment response of $\mathrm{AC}$ have been described before. Cyclooxygenase-2 (COX-2) was found to be more present in $\mathrm{AC}$ and COX-2 negative disease was found in all patients responding to RT [41]. In addition, the anti-apoptotic protein Villin1 was expressed only in cervical AC and its presence is strongly correlated with poorer survival [42]. Others suggested a role for the b-catenin pathway [43]. Exploration of these possible biomarkers of treatment response will be subject of future research.

Although pCR was low for AC in the NA-CRT group, locoregional control was $100 \%$ and $5 y$ DSS was high: $100 \%$ (compared to $75.5 \%$ for SCC; $p=0.059$ ). This emphasizes the possible role of hysterectomy after NA-CRT, already suggested by Eifel et al. in 1995 (albeit in the era before concurrent chemotherapy) [44].

\section{Conclusion}

To conclude, no statistically significant differences in relapse (incidence and pattern) and DSS between SCC and AC were found. However, a trend towards a better $5 y$ DSS of AC in the NA-CRT group is noticed, despite a significantly lower response to treatment $(\mathrm{pCR})$. The lower pCR rate in the $A C$ subgroup suggests that $A C$ is less radiosensitive than $\mathrm{SCC}$ and requires a different therapeutic strategy instead of definitive chemoradiation alone.

\section{Additional files}

Additional file 1: Table S1. Relapse pattern in the entire cohort and neo-adjuvant chemoradiation group. Table S2. Univariate analysis of DSS. Table S3. Multivariate analysis of DSS. (DOCX $26 \mathrm{~kb}$ )

\section{Abbreviations \\ AC: Adenocarcinoma; C: Chemotherapy; COX-2: Cyclooxygenase-2; CRT: Chemoradiation; DFS: Disease Free Survival; DSS: Disease Specific Survival; FIGO: Fédération Internationale de Gynécologie et d'Obstétrique; Gy: Gray; LVSI: Lymph Vascular Space Invasion; MRI: Magnetic Resonance Imaging; NA-CRT: Neo-adjuvant chemoradiation; OS: Overall Survival; pCR: Pathologic Complete Response; RT: Radiation; SCC: Squamous Cell Carcinoma; ${ }^{18}$ FDG PET-CT: ${ }^{18}$ Fluoro-deoxyglucose positron emission tomography}

\section{Acknowledgements}

VK holds a mandate for clinical and translational research funded by the Foundation against Cancer (Stichting tegen Kanker), Belgium. DJE is an Aspirant of the Research Foundation-Flanders.

\section{Funding}

The authors declare that there was no source of funding.
Availability of data and materials

The datasets used and/or analyzed during the current study are available from the corresponding author on reasonable request.

\section{Authors' contributions}

All authors contributed to the article. The first authors (CK, NE and DJE) were the leaders of database forming and data acquisition, analysis and interpretation and manuscript writing. All other authors were involved in checking the gathered data, responsible for data involved in their field of expertise: radiology (DVP), gynecologic oncology (TP and MA), pathology (VBM and VDJ), radiation oncology (NK and DNW) and medical oncology (DH) and critical interpretation of the data. The last two authors (DH and VK) were the principal leaders of the project, involved in design of the concept, data analysis and interpretation and manuscript writing/editing. All authors have read and approved the final manuscript.

\section{Ethics approval and consent to participate}

This study was approved by the ethics committee of the Ghent University Hospital (B670201628633). Due to the retrospective nature, the need for informed consent was waived.

\section{Consent for publication}

Not applicable.

\section{Competing interests}

The authors declare that they have no competing interests.

\section{Publisher's Note}

Springer Nature remains neutral with regard to jurisdictional claims in published maps and institutional affiliations.

\section{Author details}

${ }^{1}$ Department of Medical Oncology, UZ Gent, Ghent, Belgium. ${ }^{2}$ Department of Gynecology, UZ Gent, Ghent, Belgium. ${ }^{3}$ Department of Radiology, UZ Gent, Ghent, Belgium. ${ }^{4}$ Department of Pathology, UZ Gent, Ghent, Belgium.

${ }^{5}$ Department of Radiation Oncology, UZ Gent, Ghent, Belgium.

Received: 3 April 2018 Accepted: 29 October 2018

Published online: 12 November 2018

References

1. Ferlay J, Soerjomataram I, Dikshit R, Eser S, Mathers C, Rebelo M, Parkin DM, Forman D, Bray F. Cancer incidence and mortality worldwide: sources, methods and major patterns in GLOBOCAN 2012. Int J Cancer. 2015;136(5): E359-86.

2. Winer I, Alvarado-Cabrero I, Hassan O, Ahmed QF, Alosh B, Bandyopadhyay S, Thomas S, Albayrak S, Talukdar S, Al-Wahab Z, et al. The prognostic significance of histologic type in early stage cervical cancer - a multiinstitutional study. Gynecol Oncol. 2015;137(3):474-8.

3. Galic V, Herzog TJ, Lewin SN, Neugut Al, Burke WM, Lu YS, Hershman DL, Wright JD. Prognostic significance of adenocarcinoma histology in women with cervical cancer. Gynecol Oncol. 2012;125(2):287-91.

4. Hopkins MP, Morley GW. A comparison of adenocarcinoma and squamous cell carcinoma of the cervix. Obstet Gynecol. 1991;77(6):912-7.

5. Lee YY, Choi CH, Kim TJ, Lee JW, Kim BG, Lee JH, Bae DS. A comparison of pure adenocarcinoma and squamous cell carcinoma of the cervix after radical hysterectomy in stage IB-IIA. Gynecol Oncol. 2011;120(3):439-43.

6. Shimada M, Nishimura R, Nogawa T, Hatae M, Takehara K, Yamada H, Kurachi H, Yokoyama Y, Sugiyama T, Kigawa J. Comparison of the outcome between cervical adenocarcinoma and squamous cell carcinoma patients with adjuvant radiotherapy following radical surgery: SGSG/TGCU intergroup surveillance. Mol Clin Oncol. 2013:1(4):780-4.

7. Katanyoo K, Sanguanrungsirikul S, Manusirivithaya S. Comparison of treatment outcomes between squamous cell carcinoma and adenocarcinoma in locally advanced cervical cancer. Gynecol Oncol. 2012; 125(2):292-6.

8. Teke F, Yoney A, Teke M, Inal A, Urakci Z, Eren B, Zincircioglu SB, Buyukpolat MY, Ozer A, Isikdogan A, et al. Lack of any impact of histopathology type on prognosis in patients with early-stage adenocarcinoma and squamous cell carcinoma of the uterine cervix. Asian Pac J Cancer Prev. 2014;15(6):2815-9. 
9. Aoki Y, Sasaki M, Watanabe M, Sato T, Tsuneki I, Aida H, Tanaka K. High-risk group in node-positive patients with stage IB, IIA, and IIB cervical carcinoma after radical hysterectomy and postoperative pelvic irradiation. Gynecol Oncol. 2000;77(2):305-9.

10. Chen JL, Huang CY, Huang YS, Chen RJ, Wang CW, Chen YH, Cheng JC, Cheng AL, Kuo SH. Differential clinical characteristics, treatment response and prognosis of locally advanced adenocarcinoma/adenosquamous carcinoma and squamous cell carcinoma of cervix treated with definitive radiotherapy. Acta Obstet Gynecol Scand. 2014;93(7):661-8.

11. Huang YT, Wang CC, Tsai CS, Lai CH, Chang TC, Chou HH, Hsueh S, Chen CK, Lee SP, Hong JH. Long-term outcome and prognostic factors for adenocarcinoma/adenosquamous carcinoma of cervix after definitive radiotherapy. Int J Radiat Oncol Biol Phys. 2011;80(2):429-36.

12. Kaidar-Person $\mathrm{O}$, Yosefia S, Abdah-Bortnyak R. Response of adenocarcinoma of the uterine cervix to chemoradiotherapy. Oncol Lett. 2015;9(6):2791-4.

13. Zhou J, Wu SG, Sun JY, Li FY, Lin HX, Chen QH, He ZY. Comparison of clinical outcomes of squamous cell carcinoma, adenocarcinoma, and adenosquamous carcinoma of the uterine cervix after definitive radiotherapy: a population-based analysis. J Cancer Res Clin Oncol. 2017; 143(1):115-22

14. Gien LT, Covens A. Lymph node assessment in cervical cancer: prognostic and therapeutic implications. J Surg Oncol. 2009;99(4):242-7.

15. Landoni F, Maneo A, Colombo A, Placa F, Milani R, Perego P, Favini G, Ferri $L$, Mangioni C. Randomised study of radical surgery versus radiotherapy for stage Ib-lla cervical cancer. Lancet. 1997;350(9077):535-40.

16. Monk BJ, Wang J, Im S, Stock RJ, Peters WA 3rd, Liu PY, Barrett RJ 2nd, Berek JS, Souhami L, Grigsby PW, et al. Rethinking the use of radiation and chemotherapy after radical hysterectomy: a clinical-pathologic analysis of a gynecologic oncology group/southwest oncology group/radiation therapy oncology group trial. Gynecol Oncol. 2005;96(3):721-8.

17. Peters WA 3rd, Liu PY, Barrett RJ 2nd, Stock RJ, Monk BJ, Berek JS, Souhami L, Grigsby P, Gordon W Jr, Alberts DS. Concurrent chemotherapy and pelvic radiation therapy compared with pelvic radiation therapy alone as adjuvant therapy after radical surgery in high-risk early-stage cancer of the cervix. J Clin Oncol. 2000;18(8):1606-13.

18. The National Comprehensive Cancer Network. NCCN Guidelines Version 1. 2019 Cervical Cancer [https://www.nccn.org/]. Accessed 05/10/2018.

19. Potter R, Tanderup K, Kirisits C, de Leeuw A, Kirchheiner K, Nout R, Tan LT, Haie-Meder C, Mahantshetty U, Segedin B, et al. The EMBRACE II study: the outcome and prospect of two decades of evolution within the GEC-ESTRO GYN working group and the EMBRACE studies. Clin Transl Radiat Oncol. 2018;9:48-60.

20. Potter R, Georg P, Dimopoulos JC, Grimm M, Berger D, Nesvacil N, Georg D, Schmid MP, Reinthaller A, Sturdza A, et al. Clinical outcome of protocol based image (MRI) guided adaptive brachytherapy combined with 3D conformal radiotherapy with or without chemotherapy in patients with locally advanced cervical cancer. Radiother Oncol. 2011;100(1):116-23.

21. Charra-Brunaud C, Harter V, Delannes M, Haie-Meder C, Quetin P, Kerr C, Castelain B, Thomas L, Peiffert D. Impact of 3D image-based PDR brachytherapy on outcome of patients treated for cervix carcinoma in France: results of the French STIC prospective study. Radiother Oncol. 2012; 103(3):305-13.

22. Kirwan JM, Symonds P, Green JA, Tierney J, Collingwood M, Williams CJ. A systematic review of acute and late toxicity of concomitant chemoradiation for cervical cancer. Radiother Oncol. 2003;68(3):217-26.

23. Tummers P, Makar A, Vandecasteele K, De Meerleer G, Denys H, De Visschere P, Delrue L, Villeirs G, Lambein K, den Broecke RV. Completion surgery after intensity-modulated arc therapy in the treatment of locally advanced cervical cancer: feasibility, surgical outcome, and oncologic results. Int J Gynecol Cancer. 2013;23(5):877-83.

24. Vandecasteele K, De Neve W, De Gersem W, Delrue L, Paelinck L, Makar A, Fonteyne V, De Wagter C, Villeirs G, De Meerleer G. Intensity-modulated arc therapy with simultaneous integrated boost in the treatment of primary irresectable cervical cancer. Treatment planning, quality control, and clinical implementation. Strahlentherapie und Onkologie. 2009;185(12):799-807.

25. Vandecasteele K, Makar A, Van den Broecke R, Delrue L, Denys H, Lambein K, Lambert B, van Eijkeren M, Tummers P, De Meerleer G. Intensitymodulated arc therapy with cisplatin as neo-adjuvant treatment for primary irresectable cervical cancer. Toxicity, tumour response and outcome. Strahlentherapie und Onkologie. 2012;188(7):576-81.
26. Vandecasteele $K$, Tummers $P$, Makar A, van Eijkeren $M$, Delrue $L$, Denys $\mathrm{H}$, Lambert B, Beerens AS, Van den Broecke $\mathrm{R}$, Lambein $\mathrm{K}$, et al. Postoperative intensity-modulated arc therapy for cervical and endometrial cancer: a prospective report on toxicity. Int J Radiat Oncol Biol Phys. 2012;84(2):408-14.

27. RCore TE. R: A language and environment for statistical computing. [ https://www.r-project.org /]. Accessed 1 Nov 2017.

28. Bauer DF. Constructing confidence sets using rank statistics. J Am Stat Assoc. 1972;67(339):687-90.

29. Newcombe RG. Interval estimation for the difference between independent proportions: comparison of eleven methods. Stat Med. 1998;17(8):873-90.

30. Efron B. Logistic-Regression, Survival Analysis, and the Kaplan-Meier curve. J Am Stat Assoc. 1988;83(402):414-25.

31. Andersen PK, Gill RD. Cox regression-model for counting-processes - a large sample study. Ann Stat. 1982;10(4):1100-20.

32. Vinh-Hung V, Bourgain C, Vlastos G, Cserni G, De Ridder M, Storme G, Vlastos AT. Prognostic value of histopathology and trends in cervical cancer: a SEER population study. BMC Cancer. 2007;7:164.

33. Zhou J, Zhang WW, Wu SG, He ZY, Sun JY, Yang GF, Li FY. The prognostic value of histologic subtype in node-positive early-stage cervical cancer after hysterectomy and adjuvant radiotherapy. Int J Surg. 2017;44:1-6.

34. Shingleton HM, Bell MC, Fremgen A, Chmiel JS, Russell AH, Jones WB, Winchester DP, Clive RE. Is there really a difference in survival of women with squamous cell carcinoma, adenocarcinoma, and adenosquamous cell carcinoma of the cervix? Cancer. 1995;76(10 Suppl):1948-55.

35. Ayhan A, Al RA, Baykal C, Demirtas E, Ayhan A, Yuce K. Prognostic factors in FIGO stage IB cervical cancer without lymph node metastasis and the role of adjuvant radiotherapy after radical hysterectomy. Int J Gynecol Cancer. 2004; 14(2):286-92.

36. Eifel PJ, Morris M, Oswald MJ, Wharton JT, Delclos L. Adenocarcinoma of the uterine cervix. Prognosis and patterns of failure in 367 cases. Cancer. 1990; 65(11):2507-14.

37. Irie T, Kigawa J, Minagawa Y, Itamochi H, Sato S, Akeshima R, Terakawa N. Prognosis and clinicopathological characteristics of $\mathrm{lb}$-llb adenocarcinoma of the uterine cervix in patients who have had radical hysterectomy. Eur J Surg Oncol. 2000;26(5):464-7.

38. Nakanishi T, Ishikawa H, Suzuki Y, Inoue T, Nakamura S, Kuzuya K. A comparison of prognoses of pathologic stage $\mathrm{lb}$ adenocarcinoma and squamous cell carcinoma of the uterine cervix. Gynecol Oncol. 2000;79(2):289-93.

39. Quinn MA, Benedet JL, Odicino F, Maisonneuve P, Beller U, Creasman WT, Heintz AP, Ngan HY, Pecorelli S. Carcinoma of the cervix uteri. FIGO 26th annual report on the results of treatment in gynecological Cancer. Int J Gynaecol Obstet. 2006;95(Suppl 1):S43-103.

40. Rose PG, Java JJ, Whitney CW, Stehman FB, Lanciano R, Thomas GM. Locally advanced adenocarcinoma and adenosquamous carcinomas of the cervix compared to squamous cell carcinomas of the cervix in gynecologic oncology group trials of cisplatin-based chemoradiation. Gynecol Oncol. 2014;135(2):208-12.

41. Kim YB, Kim GE, Pyo HR, Cho NH, Keum KC, Lee CG, Seong J, Suh CO, Park TK. Differential cyclooxygenase-2 expression in squamous cell carcinoma and adenocarcinoma of the uterine cervix. Int J Radiat Oncol Biol Phys. 2004;60(3):822-9.

42. Nakamura E, Iwakawa M, Furuta R, Ohno T, Satoh T, Nakawatari M, Ishikawa K, Imadome K, Michikawa Y, Tamaki T, et al. Villin1, a novel diagnostic marker for cervical adenocarcinoma. Cancer Biol Ther. 2009;8(12):1146-53.

43. Imadome K, Iwakawa M, Nakawatari M, Fujita H, Kato S, Ohno T, Nakamura E, Ohkubo Y, Tamaki T, Kiyohara H, et al. Subtypes of cervical adenosquamous carcinomas classified by EpCAM expression related to radiosensitivity. Cancer Biol Ther. 2010;10(10):1019-26.

44. Eifel PJ, Burke TW, Morris M, Smith TL. Adenocarcinoma as an independent risk factor for disease recurrence in patients with stage IB cervical carcinoma. Gynecol Oncol. 1995;59(1):38-44. 